doi: 10.18484/2305-0047.2019.5.579

\title{
Н.М. МАЛАШЕНКО ${ }^{1}$, С.А. ЕСЬКОВ ${ }^{2}$, В.Т. МАЛЬКЕВИЧ ${ }^{3}$, А.В. ЗАПОЛЯНСКИЙ ${ }^{1}$, А.А. СВИРСКИЙ ${ }^{1}$, Ю.М. ГРИНЕВИЧ ${ }^{1}$, К.Ю. МАРАХОВСКИЙ ${ }^{1}$, Ю.И. ЛИННИК ${ }^{1}$, Е.С. РЯБУШКО ${ }^{1}$, А.И. ЗАМАРЕЕВ ${ }^{1}$, В.И. АВЕРИН ${ }^{2}$ ПЕРВИЧНЫЙ ВРОЖДЕННЫЙ СТЕНОЗ ТРАХЕИ У РЕБЕНКА ГРУДНОГО ВОЗРАСТА
}

\author{
Республиканский научно-практический центр детской хирургии ${ }^{1}$, \\ Минский научно-практический центр хирургии, трансплантологии и гематологии ${ }^{2}$, \\ Республиканский научно-практический центр онкологии и медицинской радиологии имени \\ Н.Н. Александрова ${ }^{3}$, \\ Белорусский государственный медицинский университет ${ }^{4}$, г. Минск, \\ Республика Беларусь
}

Первичный врожденный стеноз трахеи является редким пороком развития и встречается у 1 на 64500 новорожденных, преобладает у мальчиков. Сочетанные пороки выявляются у 80\% пациентов, из них в половине случаев - сердечно-сосудистые мальформации. Клиническая картина стеноза трахеи мало специфична, особенно у детей старше 1 месяца. В основном для всех возрастных групп можно выделить симптомы: стридор, тахипное, тахикардия, акроцианоз, периоральный цианоз, усиливающиеся при кормлении и физических нагрузках. Без хирургического лечения летальность достигает $80 \%$.

В статье представлено клиническое наблюдение ребенка 8 месяцев с множественными врожденными пороками развития: врожденный порок сердца, дивертикул и стеноз трахеи на уровне Th2, двусторонний пузырно-мочеточниковый рефлюкс 4 степени, уретерогидронефроз справа.

У данного пациента длительное время клинические проявления стеноза трахеи не были выражены, вследствие чего порок был заподозрен довольно поздно. Диагноз поставлен на основании трахеобронхоскопии, ангиопульмонографии, бронхографии и компьютерной томографии.

Пациенту выполнена циркулярная резекция грудного отдела трахеи с анастомозом «конец в конец» в условиях искусственного кровообращения. Ребенок в удовлетворительном состоянии выписан домой на 15-е сутки.

Ключевые слова: первичный врожденный стеноз трахеи, дети, клиническая картина, диагностика, резекция трахеи

Primary congenital stenosis of the trachea is a rare malformation and occurs in 1 of 64,500 newborns, prevailing in boys. Combined malformations are detected in $80 \%$ of these patients, and cardiovascular malformations are in half of the cases. The clinical picture of the tracheal stenosis is non-specific, especially in children older than 1 month. Generally, symptoms can be distinguished for all age groups: stridor, tachypnea, tachycardia, acrocyanosis, perioral cyanosis, which are aggravated during feeding and physical exertion. Without surgical treatment mortality reaches $80 \%$.

The article presents a clinical observation of an 8-year-months child with multiple congenital malformations: congenital heart disease, diverticulum and tracheal stenosis at the Th2 level, bilateral vesicoureteral reflux, grade 4, right ureterohydronephrosis.

Clinical manifestations of tracheal stenosis haven’t been marked in this patient for a long time, as a result, the defect was suspected quite late. The diagnosis was estimated by tracheobronchoscopy, angiopulmonography, bronchography and computed tomography.

The patient underwent a circular resection of the thoracic trachea with an "end-to-end" anastomosis under conditions of cardiopulmonary bypass. The child was discharged home on the 15th day in satisfactory condition.

Keywords: primary congenital tracheal stenosis, children, clinical presentation, diagnosis, resection of the trachea

Novosti Khirurgii. 2019 Sep-Oct; Vol 27 (5): 579-585

The articles published under CC BY NC-ND license

Primary Congenital Tracheal Stenosis in an Infant

N.M. Malashenko, S.A. Yeskov, V.T. Malkevich, A.V. Zapalianski, A.A. Svirsky,

Yu.M. Grinevich, K.Yu. Marakhovsky, Yu.I. Linnik, E.S. Ryabushko, A.I. Zamareev, V.I. Averin

\section{Введение}

Врожденная непроходимость дыхательных путей известна давно и является актуальнейшей проблемой хирургии детского возраста. Первичный врожденный стеноз трахеи (ПВСТ) относится к редким порокам развития и встречается у 1 на 64500 новорожденных, преобладает у маль- 
чиков. Сочетанные пороки выявляются у $80 \%$, $50 \%$ из которых - сердечно-сосудистые $[1,2]$.

Причина летальности в первые минуты жизни - критический стеноз. В более старшем возрасте - отек в зоне сужения, пневмония и др. Без лечения неблагоприятный исход достигает $80 \%[3,4]$. Эти обстоятельства требуют быстрой и отработанной диагностической тактики, а также оказания экстренной хирургической помощи.

\section{Этиология и патогенез}

Этиология порока неизвестна. Полагают, что при ПВСТ происходит нарушение развития хрящевого каркаса. Формируются замкнутые хрящевые кольца без перепончатой части, при этом диаметр трахеи не соответствует возрастной норме. Нередко наблюдаются деформация, размягчение, сращение, увеличение числа колец до 30, удлинение трахеи [5].

Классифицировать степень стеноза принято по критериям Cotton-Mayer.

Выделяют 4 типа сужений. 1. Сегментарный, вариантом этой формы является наличие в просвете поперечно расположенных перепонок по типу мембраны. 2. Воронкообразный стеноз трахеи: диаметр непосредственно ниже перстневидного хряща не изменен и конически сужается к бифуркации, зачастую захватывая главные бронхи. 3. Тотальный или протяженный, при котором главные бронхи интактны. 4. Четвертый тип характеризуется аномально высоким отхождением правого верхнедолевого бронха, левое легкое и оставшиеся доли правого легкого вентилируются посредством стенозированного перевернутого т-образного «мостовидного» бронха [6]. Уровень и протяженность порока сугубо индивидуальны.

\section{Клиника и диагностика}

Клиническая картина может проявляться в любом возрасте. Для нее характерен стридор шумное свистящее дыхание, которое слышно, как на вдохе, так и на выдохе. Это зависит от степени стеноза и компенсаторных возможностей организма. Sankott (1922) обнаружил стеноз трахеи в виде находки, на секционном исследовании у мужчины 36 лет, при жизни у которого клинических проявлений не было, и который умер по иным причинам (Цит. по М.И. Перельман [5]]).

Дети с III степенью обструкции рождаются с признаками тяжелой дыхательной недостаточности (ДН) (7-9 и более баллов по шкале Даунаса для доношенных) [7]: стридор, акроцианоз, периоральный цианоз, одышка, дисфония, сухие хрипы, втяжение податливых мест грудной клетки. В таких случаях требуется активная респираторная поддержка с жесткими параметрами вентиляции (FiO2 100\%), наблюдаются затруднения при проведении интубационной трубки, а попытки экстубации и перевод на спонтанное дыхание безуспешны.

При II степени и меньше имеются незначительные проявления ДН, которые успешно корригируются, специфические же симптомы отсутствуют. Как правило, такие дети остаются необследованными или имеют ложный диагноз бронхиальной астмы. Родители часто замечают, что ребенок быстро устает при приеме пищи, играх и старается уменьшить их продолжительность. При физической нагрузке наблюдается нарастающая одышка вплоть до кратковременной потери сознания. Голос может быть негромким, осиплым, крик затруднен. Пациенты часто болеют рецидивирующими и затяжными заболеваниями дыхательной системы, в один из эпизодов которых нарастает ДН и может быть заподозрен порок. Наибольшее количество таких случаев приходится на 3-8 месяцы жизни [7].

Помощь в диагностике оказывают рентгенологические и эндоскопические методы.

Золотым стандартом принято считать компьютерную томографию (КТ), которая точно визуализирует уровень, протяженность, степень сужения, толщину стенки трахеи, наличие перипроцесса [8]. Полностью исключает сосудистую составляющую порока КТ-ангиография. Обзорная рентгенография грудной клетки и брохнография являются вспомогательными методами. Стоит подчеркнуть, что ларинготрахеобронхоскопия (ЛТБС) - это лечебно-диагностический метод, позволяющий уточнить диаметр просвета, уровень сужения, оценить состояние слизистой и вне гнойно-воспалительного периода оказать хирургическую помощь [9].

\section{Лечение}

При респираторно значимых формах ПВСТ консервативное лечение неэффективно, возможна только поддерживающая терапия. В настоящее время существуют два метода лечения ПВСТ: эндоскопический и оперативный.

Первый применяется в случаях, когда имеется очень непротяженное сужение или мембрана, стеноз I или II степени. Используются следующие малоинвазивные вмешательства: бужирование с или без пролонгированной интубацией, стентирование, баллонная дилатация, лазерная вапоризация и т.д. Эффективность эндоскопического метода, по данным неко- 
торых авторов, достигает 100\% [10]. Он также является методом расширения зоны анастомоза после трахеопластики.

При оперативных подходах к лечению ПВСТ оптимальным методом считается циркулярная резекция трахеи (ЦРТ). Однако к ней существует ряд абсолютных противопоказаний: протяженность стеноза более 7-8 полуколец (при широкой мобилизации), малая отдаленность от голосовых связок, многоуровневые стенозы, двусторонний паралич возвратного нерва, обширный трахеопищеводный свищ, нарушение разделительной функции гортани [9]. Протяженные сужения принято корригировать методом скользящей трахеопластики, предложенной V. Tsang et al. (цит. по K. Komori et al. [11]). Наименее распространенные методы в таких ситуациях: продольное вшивание заплаты из реберного хряща по Кимура (1982) или аутоперикарда, кожная реконструкция трахеи по Grillo (используется при отсутствии возможности сформировать просвет из собственной ткани органа) и др. [4, 12, 13]. При 4-м типе стенозов используется метод резекции мостовидного бронха и формирования неотрифуркации [6].

Стоит отметить, что, по данным литературы, летальность после радикального хирургического лечения у детей до 1 месяца достигает $73 \%$, а после одного месяца - 19\% [14]. При циркулярной резекции неблагоприятный исход составляет $6,7 \%$, при трахеопластике $-39,5 \%$ [13].

\section{Клинический случай}

Пациент, 8 месяцев, был переведен в РНПЦ детской хирургии из областной детской больницы 24.10.2018 с целью дообследования и определения тактики лечения с основным клиническим диагнозом «Множественные врожденные пороки развития (МВПР): дивертикул и стеноз трахеи на уровне Th2. Сужение просвета сегментарных бронхов В1-В2 верхней доли левого легкого. Участки пневмофиброза обоих легких. Врожденный порок сердца (ВПС): дефект межжелудочковой перегородки, открытое овальное окно. Ускорение кровотока в легочной артерии, недостаточность кровообращения 1 ст. Двусторонний пузырно-мочеточниковый рефлюкс 4 степени. Уретерогидронефроз справа. Осложнение: двусторонний гнойный эндобронхит. Сопутствующий: транзиторный гипотиреоз, стадия субкомпенсации».

Из анамнеза известно, что ребенок родился недоношенным (35-36 недель) при помощи кесарева сечения, 2-й плод из двойни, с массой тела 2530 грамм, беременность протекала нормально. Из родильного зала был переведен в отделение анестезиологии и реанимации $(\mathrm{OАиР)} \mathrm{с} \mathrm{клиникой} \mathrm{ДН} \mathrm{и} \mathrm{сердечно-сосудистой}$ недостаточности $(\mathrm{CCH})$. У ребенка наблюдались стридор, тахипное, тахикардия, акроцианоз, периоральный цианоз. Эндотрахеальная респираторная поддержка не потребовалась, проводилась подача увлажненного кислорода через маску. После обследований такое состояние объяснялось наличием врожденного порока сердца и узкими носовыми ходами. На 10-е сутки был переведен в отделение недоношенных новорожденных, на 40-е - выписан домой без признаков ДН и ССН. В первые 6 месяцев жизни пациент многократно госпитализировался с диагнозом острого пиелонефрита. После 6 месяцев - с обструктивными бронхитами (ОБ). В момент последнего пребывания в областной больнице были выполнены следующие исследования: ЛТБС, компьютерная томография, рентгенография грудной клетки после чего был выявлен ПВСТ. Сбор уточняющего анамнеза (со слов матери, шумное дыхание сохранялось с рождения).

При поступлении в РНПЦ детской хирургии состояние средней тяжести. Сознание, аппетит, сон не нарушены, нормотермия. Со стороны органов пищеварения патологии не выявлено. Частота сердечных сокращений (ЧСС) 130 ударов в минуту. Дыхание самостоятельное, жесткое, проводится с обеих сторон, шумное, стридорозное. Выслушиваются влажные двухсторонние хрипы, как рассеянные, так и проводные. Тахипноэ до 50 дыхательных движений (ДД) в минуту. Стул и диурез в норме.

На следующий день, 25.10.18, ребенку была выполнена ЛТБС. Заключение: стеноз трахеи с просветом до 1,8 мм (эндоскоп проведен за зону сужения), проксимальнее которого визуализируется дивертикул трахеи. После чего пациентке были проведены ангиопульмонография, бронхография, а 01.11.18 выполнено повторное КТ. Заключение: диаметр интактной трахеи (ниже перстневидного хряща) до 6,7 мм; на уровне Th3-4 - стеноз протяженностью до 9 мм и диаметром 1,3 мм, по верхнему краю стеноза располагается дивертикул длиной до 6 мм; объемное уменьшение верхней доли правого легкого (рис. 1).

Консилиумом были выставлены показания к хирургической коррекции порока.

В операционной 07.11.18 выполнена продольная срединная стернотомия. Доступ к проблемной зоне произведен после подключения аппарата искусственного кровообращения (АИК), без лигирования и пересечения магистральных сосудов, через задний листок 


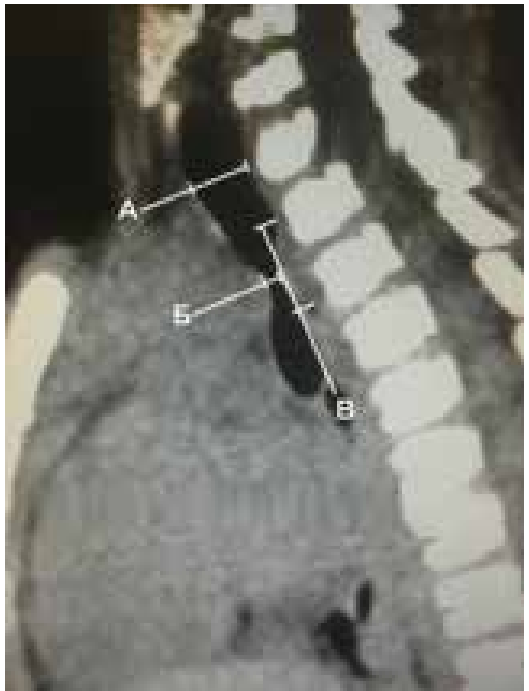

Рис. 1. КТ органов грудной клетки, боковая проекция: А - диаметр трахеи ниже перстневидного хряща, Б - диаметр на уровне стеноза, В - протяженность стеноза.

перикарда. Мобилизация средней и нижней трети трахеи, главных бронхов. Выявлена зона стеноза протяженностью 8 миллиметров с дивертикулом, расположенным выше нее. Выполнена ЦРТ выше и ниже зоны последней на 5 мм, наложен анастомоз «конец в конец» (рис. 2). Задняя стенка трахеи ушита непрерывным швом, фиброзно-хрящевая часть за ligamentum anularia - восьмиобразными швами Surgipro 5/0 (рис. 3). Интраоперационная ЛТБС: анастомоз состоятелен, просвет достаточный. Дренажи в правую плевральную полость и переднее средостение. Продолжительность этапа реконструкции трахеи с сопутствующей санационной бронхоскопией составила 30 минут.

Послеоперационный период протекал без

Рис. 2. Трахея пересечена и взята на держалки за главные бронхи (вид со стороны анестезиолога).

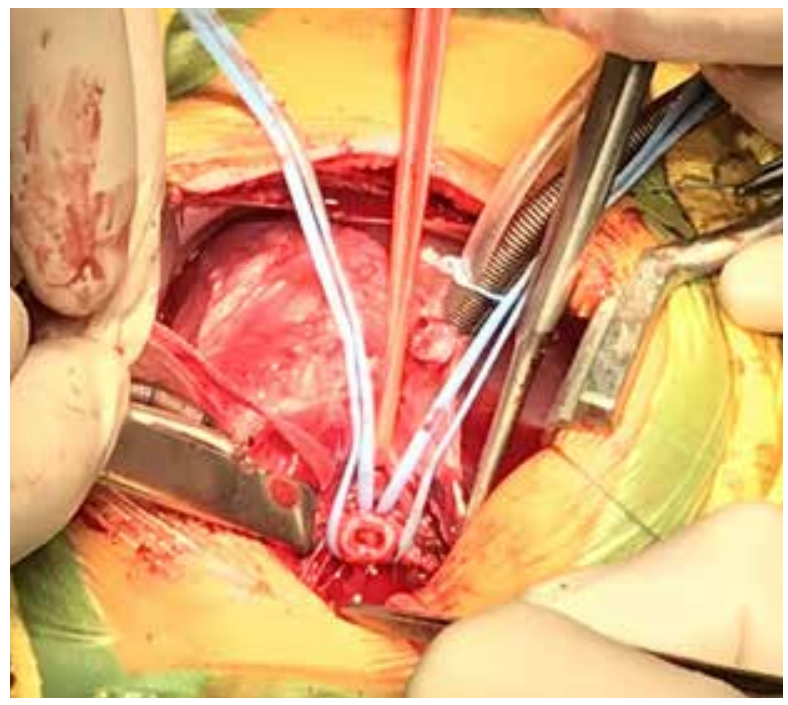

осложнений. Экстубация на 2-е сутки. Перевод из ОАиР на 9-е сутки. Ребенок в удовлетворительном состоянии выписан домой на 15-е сутки. В настоящее время находится под наблюдением педиатра и детского хирурга по месту жительства. Клиники ДН не отмечается.

\section{Обсуждение}

В нашем сообщении мы хотели обратить внимание на возраст пациента, длительный анамнез заболевания и компенсаторные возможности детского организма. Быстрая адаптация и компенсация организма к ВПС и стенозу III степени не позволили заподозрить врожденный порок развития трахеи, пока он не достиг уровня явных клинических проявлений, т. е. декомпенсации. Течение болезни у данного ребенка больше характерно для стеноза трахеи I или II, хотя, по данным литературы, такого рода патология проявляется сразу при рождении и протекает тяжело. Поэтому у сложных в диагностическом плане пациентов необходимо помнить о возможном наличии анатомических нарушений дыхательных путей. В случаях приобретенной патологии либо врожденного порока воздухопроводящих путей основным методом диагностики является КТ и ЛТБС.

Ключевыми моментами в выборе тактики лечения были оперативный доступ и интраоперационное обеспечение дыхательной функции. На наш взгляд, в конкретной клинической ситуации оптимальным оперативным доступом оказалась полная срединная стернотомия, поскольку благодаря этому подходу было обеспечено на первом этапе беспрепятственное подключение АИК и на втором этапе - бла-

Рис. 3. Трахея ушита, в нижнем углу раны видны восьмиобразные швы, наложенные на переднюю губу (вид со стороны анестезиолога).

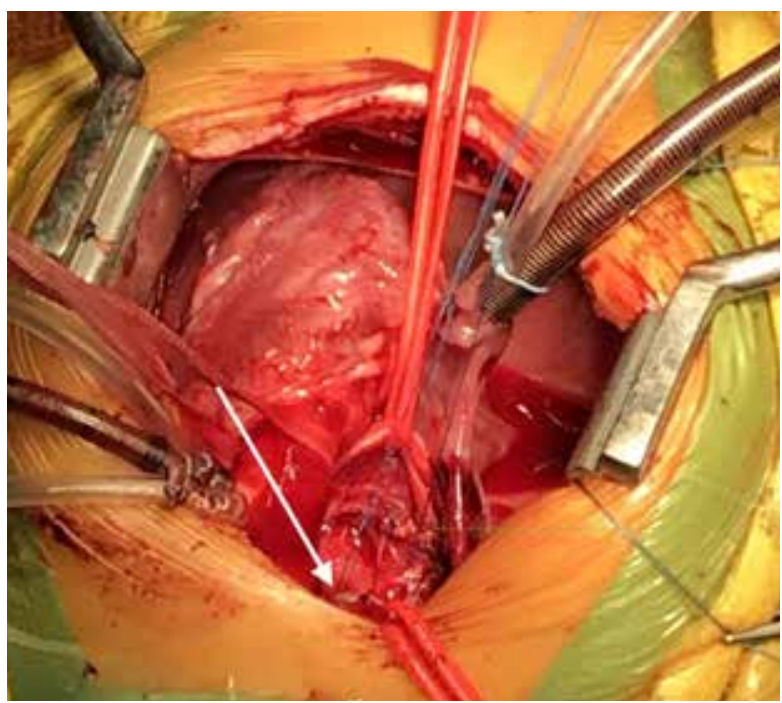


гоприятные условия для резекции трахеи с формированием анастомоза без вентиляционной поддержки легких. Положительным преимуществом данного доступа явилась полная бескровная мобилизация трахеи, бифуркации трахеи и обоих главных бронхов, что позволило избежать излишнего натяжения зоны трахеотрахеального анастомоза.

При развитии легочных осложнений предполагалось резервное использование экстракорпоральной мембранной оксигенации.

Выработанный алгоритм оказался эффективным и может быть применим в хирургии детского возраста при лечении врожденных пороков внутригрудного отдела трахеи.

\section{Заключение}

Представленный случай описывает редкое клиническое наблюдение и успешное лечение порока развития трахеи у ребенка.

Диагностика, выбор лечебной тактики, а также эффективная оперативная коррекция с последующим ведением пациентов с данным пороком может быть осуществлена только при мультидисциплинарном подходе с привлечением квалифицированного персонала и уникального оборудования высокоспециализированных центров.

\section{Финансирование}

Финансовой поддержки со стороны компаний-производителей лекарственных препаратов, медицинской техники авторы не получали.

\section{Конфликт интересов}

Авторы заявляют, что конфликт интересов отсутствует.

\section{Согласие пациента на публикацию}

Родители пациента дали согласие на публикацию сообщения и размещение в интернете информации о характере заболевания, проведенном лечении и его результатах с научной и образовательной целями.

\section{ЛИТЕРАТУРА}

1. Antón-Pacheco JL, Morante R. Operative or non-operative treatment of congenital tracheal stenosis: is there something new? J Thorac Dis. 2017 Dec;9(12):4878-80. doi: 10.21037/jtd.2017.11.75

2. Herrera P, Caldarone C, Forte V, Campisi P, Holtby H, Chait P, Chiu P, Cox P, Yoo SJ, Manson D, Kim PC. The current state of congenital tracheal stenosis. Pediatr Surg Int. 2007 Nov;23(11):1033-44. doi: $10.1007 / \mathrm{s} 00383-007-1945-3$

3. Hoffer ME, Tom LW, Wetmore RF, Handler SD, Potsic WP. Congenital tracheal stenosis. The otolaryngologist's perspective. Arch Otolaryngol Head Neck Surg. 1994 Apr;120(4):449-53. doi:10.1001/ archotol.1994.01880280077015

4. Руденко ЄО. Повні хрящові кільця - рідкісній та важкий стеноз трахеї у дітей. Мінііинвазивне та хирургічне лікуванне. Хірургія Дитячого Вику. 2018;(1):66-74. doi 10.15574/PS.2018.58.66

5. Перельман МИ. Хирургия трахеи. Москва, РФ: Медицина; 1972. 190 c. https://studfiles.net/ preview/1215219/

6. Grillo HC. Surgery of the trachea and bronchi. London, UK: BC Decker Inc Hamilton; 2004. 872 p. 7. Волосянко АБ, Ходан ВВ, Багрій ММ, Кузик СВ, Навроцька ЛБ, Ільків МВ. Клінічна характеристика стенотичних уражень верхніх відділів дихального тракту у дітей раннього віку [Электронный ресурс]. Здоровье Ребенка. 2012;(1):66-69. [Дата обращения 01 Янв 2019]. http://www.mif-ua.com/archive/ article $/ 26008$

8. Шевченко ЮВ, Селиверстов ПВ, Нечаев ЕВ. Изометрия стенозов гортани и трахеи с помощью мультиспиральноий компьютерной томографии [Электронный ресурс]. Сиб Мед Журн. 2014;(1):11721. [Дата обращения 20 Окт 2018]. http://smj.ismu. baikal.ru/index.php/-osn/issue/view/29/2014-1

9. Татур АА. Циркулярная резекция трахеи в лечении ее рубцовых стенозов [Электронный ресурс]. Мед Журн. 2014;(1):119-24. [Дата обращения 25 Окт 2018]. https://www.bsmu.by/medicaljournal/ category47/

10. Кривченя ДЮ, Руденко ЕО, Дубровин АГ. Миниинвазивная коррекция стеноза дыхательных путей у детей. Перинатология u Педиатрия. 2018;(1):118-24. doi: 10.15574/PP.2018.73.118

11. Komori K, Toma M, Shimojima N, Yamamoto $Y$, Uto K, Ogata S, Kano M, Hirobe S. Laryngeal release with slide tracheoplasty for long-segment congenital tracheal stenosis. Gen Thorac Cardiovasc Surg. 2015 Oct;63(10):583-85. doi: 10.1007/s11748-013-0329-y

12. Tsugawa C, Kimura K, Muraji T, Nishijima E, Matsumoto Y, Murata H. Congenital stenosis involving a long segment of the trachea: further experience in reconstructive surgery. $J$ Pediatr Surg. 1988 May;23(5):471-75. doi: 10.1016/S0022-3468(88)80451-2 13. Backer CL, Holinger LD. A history of pediatric tracheal surgery. World J Pediatr Congenit Heart Surg. 2010 Oct;1(3):344-63. doi: 10.1177/2150135110381602 14. Chiu PP, Kim PC. Prognostic factors in the surgical treatment of congenital tracheal stenosis: a multicenter analysis of the literature. J Pediatr Surg. 2006 Jan;41(1):221-25; discussion 221-5. doi: 10.1016/j. jpedsurg.2005.10.043

\section{REFERENCES}

1. Antón-Pacheco JL, Morante R. Operative or non-operative treatment of congenital tracheal stenosis: is there something new? J Thorac Dis. 2017 Dec;9(12):4878-80. doi: 10.21037/jtd.2017.11.75

2. Herrera P, Caldarone C, Forte V, Campisi P, Holtby $\mathrm{H}$, Chait P, Chiu P, Cox P, Yoo SJ, Manson D, Kim PC. The current state of congenital tracheal stenosis. Pediatr Surg Int. 2007 Nov;23(11):1033-44. doi: $10.1007 / \mathrm{s} 00383-007-1945-3$ 
3. Hoffer ME, Tom LW, Wetmore RF, Handler SD, Potsic WP. Congenital tracheal stenosis. The otolaryngologist's perspective. Arch Otolaryngol Head Neck Surg. 1994 Apr;120(4):449-53. doi:10.1001/ archotol.1994.01880280077015

4. Rudenko CO. Complete cartilage rings - a rare and severe trachea stenosis in children/ Minimally invasive and surgical treatment. Khirurgiia Ditiachogo Viku. 2018;(1):66-74. doi 10.15574/PS.2018.58.66 (in Ukr.) 5. Perel'man MI. Khirurgiia trakhei. Moscow RF: Meditsina; 1972. 190 p. https://studfiles.net/ preview/1215219 (in Russ.)

6. Grillo HC. Surgery of the trachea and bronchi. London, UK: BC Decker Inc Hamilton; 2004. 872 p. 7. Volosianko AB, Khodan VV, Bagrii MM, Kuzik SV, Navrots'ka LB, Il'kiv MV. Klinichna kharakteristika stenotichnikh urazhen' verkhnikh viddiliv dikhal'nogo traktu u ditei rann'ogo viku [Elektronnyi resurs]. Zdorov'e Rebenka. 2012;(1):66-69. [Data obrashcheniia 01 Ianv 2019]. http://www.mif-ua.com/archive/article/26008 (in Ukr.)

8. Shevchenko IuV, Seliverstov PV, Nechaev EV. MCT-isometry of stenoses of a throat and trachea. [Elektronnyi resurs]. Sib Med Zhurn. 2014;(1):11721. [Data obrashcheniia 20 Okt 2018]. http://smj. ismu.baikal.ru/index.php/osn/issue/view/29/2014-1 (in Russ.)

\section{Адрес для корреспонденции}

220013, Республика Беларусь, г. Минск,

пр. Независимости, д. 64,

Республиканский научно-практический

центр детской хирургии,

отделение плановой хирургии,

тел.: +375 293868179 ,

e-mail: kisandra@yandex.ru,

Малашенко Никита Михайлович

\section{Сведения об авторах}

Малашенко Никита Михайлович, врач-детский хирург хирургического отделения № 3, Республиканский научно-практический центр детской хирургии, г. Минск, Республика Беларусь. https://orcid.org/0000-0002-4340-7623

Еськов Сергей Александрович, к.м.н., врачторакальный хирург, заведующий торакальным отделением, Минский научно-практический центр хирургии, трансплантологии и гематологии, г. Минск, Республика Беларусь. https://orcid.org/0000-0001-9957-1644

Малькевич Виктор Тихонович, д.м.н., доцент, врачторакальный хирург, заведующий лабораторией торакальной онкопатологии, Республиканский научно-практический центр онкологии и медицинской радиологии имени Н.Н. Александрова, агрогородок Лесной, Минский район, Республика Беларусь. https://orcid.org/0000-0001-6138-8713

Заполянский Андрей Валентинович, к.м.н., врачдетский хирург, заведующий отделом хирургии, Республиканский научно-практический центр детской хирургии, г. Минск, Республика Беларусь. https://orcid.org/0000-0001-6854-7625

Свирский Александр Анатольевич, к.м.н., доцент, врач-детский хирург, заместитель директора по лечебной работе, Республиканский научно-
9. Tatur AA. Circular tracheal resection in treatment of cicatricial stenosis [Elektronnyi resurs]. Med Zhurn. 2014;(1):119-24. [Data obrashcheniia 25 Okt 2018]. https://www.bsmu.by/medicaljournal/category47/ (in Russ.)

10. Krivcenya DU, Rudenko EO, Dubrovin A.G. Minimally invasive treatment of airway stenoses in children. Perinatologiia $i$ Pediatriia. 2018;(1):118-24. doi: 10.15574/PP.2018.73.118 (in Ukr.)

11.Komori K, Toma M, Shimojima N, Yamamoto Y, Uto K, Ogata S, Kano M, Hirobe S. Laryngeal release with slide tracheoplasty for long-segment congenital tracheal stenosis. Gen Thorac Cardiovasc Surg. 2015 Oct;63(10):583-85. doi: 10.1007/s11748-013-0329-y

12. Tsugawa $\mathrm{C}$, Kimura $\mathrm{K}$, Muraji $\mathrm{T}$, Nishijima E, Matsumoto Y, Murata H. Congenital stenosis involving a long segment of the trachea: further experience in reconstructive surgery. $J$ Pediatr Surg. 1988 May;23(5):471-75. doi: 10.1016/S0022-3468(88)80451-2 13. Backer CL, Holinger LD. A history of pediatric tracheal surgery. World J Pediatr Congenit Heart Surg. 2010 Oct;1(3):344-63. doi: 10.1177/2150135110381602 14. Chiu PP, Kim PC. Prognostic factors in the surgical treatment of congenital tracheal stenosis: a multicenter analysis of the literature. J Pediatr Surg. 2006 Jan;41(1):221-25; discussion 221-5. doi: 10.1016/j. jpedsurg.2005.10.043

\section{Address for correspondence}

220013, The Republic of Belarus,

Minsk, Independence Ave., 64,

Children's Surgery National

Applied Research Hospital.

Tel. +3752938681 79,

e-mail: kisandra@yandex.ru,

Nikita M. Malashenko

\section{Information about the authors}

Malashenko Nikita M., Pediatric Surgeon, Surgical Department №3, Children’s Surgery National Applied Research Hospital, Minsk, Republic of Belarus.

https://orcid.org/0000-0002-4340-7623

Yeskov Sergey A., PhD, Thoracic Surgeon, Head of the Thoracic Department, Minsk Scientific and Practical Center for Surgery, Transplantology and Hematology, Minsk, Republic of Belarus.

https://orcid.org/0000-0001-9957-1644

Malkevich Viktar T., MD, Associate Professor, Thoracic Surgeon, Head of the Laboratory of the Thoracic Cancer Pathology, N.N. Alexandrov National Cancer Centre of Belarus, Lesnoy, Minsk District, Republic of Belarus. https://orcid.org/0000-0001-6138-8713

Zapalianski Andrei V., PhD, Pediatric Surgeon, Head of the Surgery Department, Children's Surgery National Applied Research Hospital, Minsk, Republic of Belarus. https://orcid.org/0000-0001-6854-7625

Svirsky Aliaksandr A., PhD, Associate Professor, Pediatric Surgeon, Deputy Director for Medical Work, Children's Surgery National Applied Research Hospital, Minsk, Republic of Belarus.

https://orcid.org/0000-0001-6323-6537

Grinevich Yuri M., PhD, Associate Professor, Pediatric Surgeon, Head of the Surgical Department №4, Children's Surgery National Applied Research Hospital, 
практический центр детской хирургии, г. Минск, Республика Беларусь.

https://orcid.org/0000-0001-6323-6537

Гриневич Юрий Мечиславович, к.м.н., доцент, врач-детский хирург, заведующий хирургическим отделением № 4, Республиканский научно-практический центр детской хирургии, г. Минск, Республика Беларусь.

https://orcid.org/0000-0003-4376-9971

Мараховский Кирилл Юрьевич, к.м.н., врачдетский хирург, заведующий диагностическим отделом, Республиканский научно-практический центр детской хирургии, г. Минск, Республика Беларусь. https://orcid.org/0000-0002-4191-6053

Линник Юрий Иванович, врач-детский кардиохирург, заведующий отделом детской кардиохирургии, Республиканский научно-практический центр детской хирургии, г. Минск, Республика Беларусь. https://orcid.org/0000-0002-8281-3149

Рябушко Елена Станиславовна, врач-перфузиолог, отделение анестезиологии и реанимации №1, Peспубликанский научно-практический центр детской хирургии, г. Минск, Республика Беларусь.

https://orcid.org/0000-0002-6248-9847

Замареев Александр Иванович, врач-анестезиологреаниматолог, заведующий отделением анестезиологии и реанимации №1, Республиканский научнопрактический центр детской хирургии, г. Минск, Республика Беларусь.

https://orcid.org/0000-0002-3712-8505

Аверин Василий Иванович, д.м.н., профессор, заведующий кафедрой детской хирургии, Белорусский государственный медицинский университет, г. Минск, Республика Беларусь.

https://orcid.org/0000-0003-3343-8810

\section{Информация о статье}

Поступила 15 мая 2019 г.

Принята в печать 9 сентября 2019 г.

Доступна на сайте 1 ноября 2019 г.
Minsk, Republic of Belarus.

https://orcid.org/0000-0003-4376-9971

Marakhovsky Kirill Yu., PhD, Pediatric Surgeon, Head of the Diagnostic Department, Children's Surgery National Applied Research Hospital, Minsk, Republic of Belarus.

https://orcid.org/0000-0002-4191-6053

Linnik Yuri I., Pediatric Cardiovascular Surgeon, Head of the Department of Pediatric Cardiovascular Surgery, Children's Surgery National Applied Research Hospital, Minsk, Republic of Belarus.

https://orcid.org/0000-0002-8281-3149

Ryabushko Elena S., Perfusiologist, the Department of Anesthesiology and Resuscitation №1, Children’s Surgery National Applied Research Hospital, Minsk, Republic of Belarus.

https://orcid.org/0000-0002-6248-9847

Zamareev Aliaksandr I., Anesthesiologist - Resuscitator, Head of the Department of Anesthesiology and Resuscitation №1, Children’s Surgery National Applied Research Hospital, Minsk, Republic of Belarus.

https://orcid.org/0000-0002-3712-8505

Averin Vasily I., MD, Professor, Head of the Department of Pediatric Surgery, Belarusian State Medical University, Minsk, Republic of Belarus. https://orcid.org/0000-0003-3343-8810

\section{Article history}

Arrived: 15 May 2019

Accepted for publication: 9 September 2019

Available online: 1 November 2019 